\title{
The effect of hyaluronate-carboxymethyl-cellulose on the formation of postoperative adhesion in stomach visceral peritoneum damage
}

\author{
Gemici $\mathrm{K}^{1}$, Kucukpinar $\mathrm{T}^{2}$, Cifter $\mathrm{C}^{3}$, Okus $\mathrm{A}^{1}$, Ay $\mathrm{S}^{4}$ \\ Mevlana University Faculty of Medicine Department of General Surgery, Konya, Turkey. \\ drkazimgemici@hotmail.com
}

\begin{abstract}
Objective: In this study, we aimed at investigating the effect of placing hyaluronate- carboxymethylcellulose membrane (HCMC) on the formation of adhesion postoperatively in a damaged area in the peritoneum of the anterior stomach wall.

Methods: The study was conducted on 30 rabbits. A transverse peritoneal damage was inflicted on the stomach anterior walls of all rabbits. In the first treatment group, HCMC was placed on the sutured anterior wall of stomach of 15 rabbits. In the second control group, on the other hand, no treatment was conducted on 15 rabbits. On the 30th day after the operation, relaparatomy was performed on the rabbits and adhesions were evaluated by an independent surgeon according to seriousness and prevalence scores.

Results: There were postoperative adhesions (POA) in $12(80 \%)$ rabbits in the control group. On the other hand, there were POA in 5 rabbits (33.3\%) in the treatment group. In the treatment group, adhesion was totally prevalent in 2 rabbits $(13.3 \%)$, whereas this ratio was $7(46.6 \%)$ in the control group $(p<0.01)$.

Conclusions: The study suggested that the use of hyaluronate-carboxymethyl-cellulose could be beneficial on damaged peritoneum surfaces following abdominal surgery in order to reduce POA development to a minimum (Tab. 3, Fig. 3, Ref. 22). Text in PDF www.elis.sk.

Key words: hyaluronate-carboxymethyl-cellulose, Seprafilm®, surgery, adhesions.
\end{abstract}

Abdominal adhesions are a frequently observed complication of open and laparoscopic surgery. Especially general surgeons and gynecologists frequently encounter postoperative adhesions (POA) following an intraabdominal surgery. The incidence of POA was reported to be $93 \%$ in upper abdominal surgeries and 67-93\% in lower abdominal surgeries (1). We believe that efforts aimed at preventing adhesions can be improved when the process of recovery of peritoneum is better understood (2). The most appropriate adhesion prevention efforts are the ones made within the first seven days, when the peritoneum recovery process is faster (3).

Many barrier agents have been tried in recent years to prevent POAs, but very few of them have proven to be effective and reliable. These are Interceed ${ }^{\circledR}$ (oxidized regenerated cellulose), Seprafilm ${ }^{\circledR}$ (HA-CMC) and Goretex surgical membrane ${ }^{\circledR}$ (expanded polytetra-fluoroethylene). Seprafilm ${ }^{\circledR}$ (HA-CMC) is one of the most widely used. Seprafilm ${ }^{\circledR}$ began to be used worldwide after it was approved by the FDA in 1996. HA-CMC membrane turns into gel form within 24-48 hours of its application and is reabsorbed

${ }^{1}$ Mevlana University Faculty of Medicine Department of General Surgery, Konya, Turkey, ${ }^{2}$ Ankara Yildirim Beyazit Education Hospital Department of First General Surgery, Ankara, Turkey, ${ }^{3}$ Gazi University Department of General Surgery, Ankara, Turkey, and ${ }^{4}$ Konya Training and Research Hospital, Department of General Surgery, Konya, Turkey

Address for correspondence: K. Gemici, Aksinne mahallesi Esmetas, sokak No:16, Meram/Konya, Turkey,

Phone: $\quad+0.90 .4444200$, Fax: $\quad+0.90 .3323205630$ where it was applied by the 7th day (14). Radioactive studies indicate that it takes the body 28 days to become rid of Seprafilm ${ }^{\circledR}$ (4).

The aim of this study was to evaluate the effectiveness of Seprafilm in prevention of POA.

\section{Material and methods}

This study was conducted on 30 New Zealand type rabbits of both sexes, each with an average weight of 1,625 gr. The study was performed in accordance with the principles of "Helsinki Universal Animal Rights Declaration”. The rabbits, which were fed standard pellet feed and tap water, were left unary for 6 hours before the surgical intervention. The subjects were divided into the two groups, namely the treatment group and the control group, each with 15 members. All of the subjects were anesthetized during spontaneous breathing, through intramuscular injection on the hind leg's upper thigh, using $50 \mathrm{mg} / \mathrm{kg}$ ketamine hydrochloride (Ketalar-Parke Davis ${ }^{\circledR}$ ) and 10 mg/kg Xylazin (Xylazine ${ }^{\circledR}-20$ injection, Butle Company, Columbus, $\mathrm{OH}$ ). After the abdomen was shaved, the skin was cleaned with betadine and the abdomen was entered with a $10 \mathrm{~cm}$ midline incision in sterile conditions. The stomach was revealed, and then damage was inflicted on the peritoneum with a $3 \mathrm{~cm}$ transverse incision on the visceral peritoneum of the anterior stomach wall. An effort was made to create suture ischemia and a foreign object reaction, using 4 / 0 atraumatic silk suture on the damaged peritoneum with intervals of $0.5 \mathrm{~cm}$ 


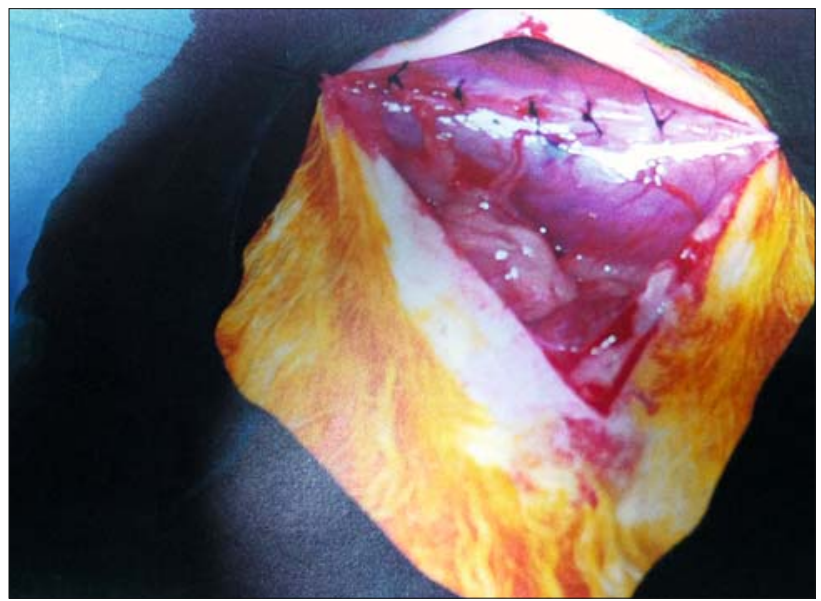

Fig. 1. Peritoneum incision (sutured with 4 / 0 silk).

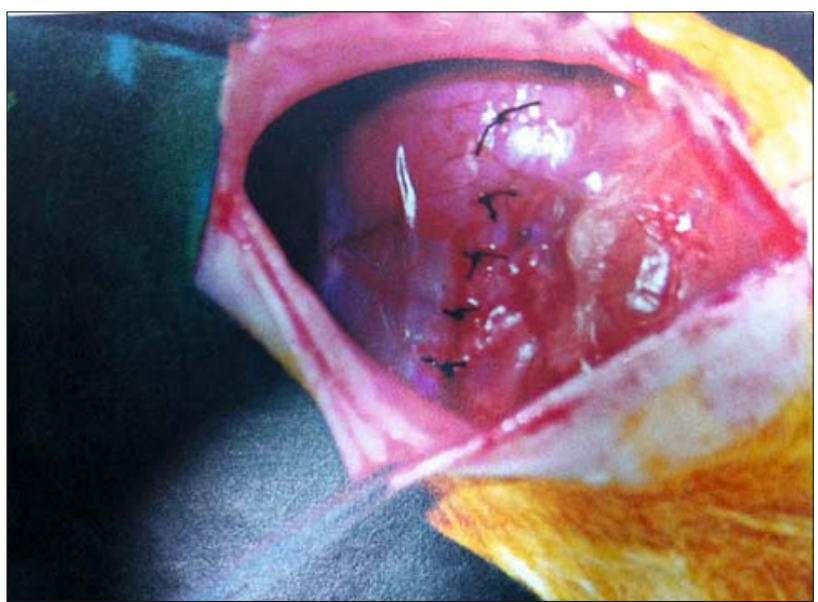

Fig. 2. Seprafilm® application.

(Fig. 1). Before the abdomens of the 15 subjects in the treatment group were recovered, the sutured stomach front wall was covered with 6 × 3 cm Seprafilm ${ }^{\circledR}$ (Genzym Corporation, MA) extending beyond the damaged area by $1 \mathrm{~cm}$ on all sides, and thus the damaged area was separated physically from the anterior abdominan wall and the other intraabdominal organs (Fig. 2). Seprafilm ${ }^{\circledR}$ was not applied to the control group. The abdomen was covered with 3 / 0 silk suture. The incision was cleaned with betadine and left open. The rabbits began to be fed standard feed and water in the 6 th hour after the surgery. The abdomens were entered on the 30th day of the surgery through the previous incision using the same anesthetic method, and the adhesions that formed on the anterior stomach wall were scored by an independent surgeon on the basis of prevalence and seriousness (Tab. 1) (5).

Tab. 1. Adhesion of prevalence and seriousness.

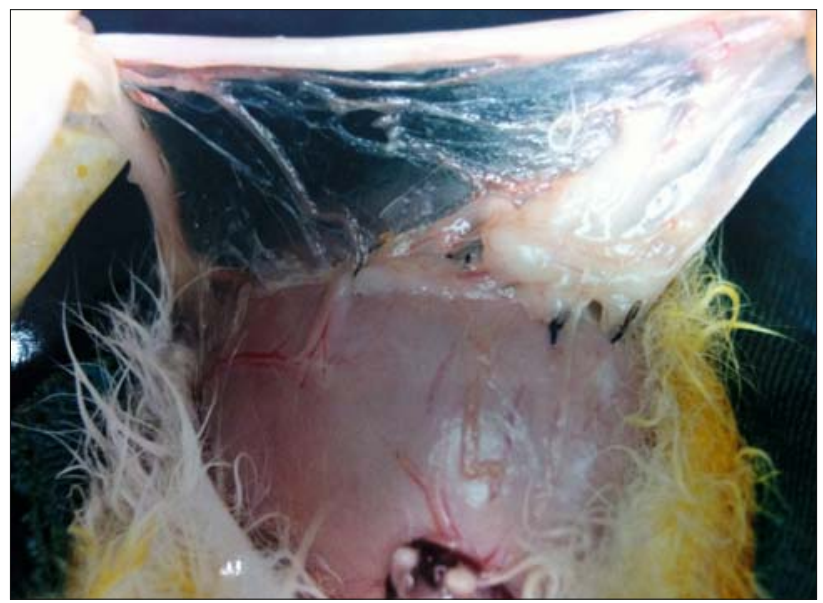

Fig. 3. Adhesion prevalence score in the control group: 3, seriousness score 3.

\section{Statistics}

In the statistical analysis, SPSS 15.0 for Windows was used. For the comparison of the presence and the seriousness of adhesions, chi-square test was used. The p value lower than 0.05 was considered to be statistically significant.

\section{Results}

Adhesions were observed in 12 (80\%) of the 15 rabbits in the control group, whereas adhesions were observed in only 5 (33.3\%) of the 15 rabbits in the treatment group. This difference was statistically significant ( $p<0.05$ ). Cohesive vascular adhesion was not seen in the treatment group, while it was seen in 3 (20\%) of the control group ( $<$ 0.01) (Fig. 3). No statistically significant difference was found between the formation of filmy avascular adhesion in the treatment group, where Seprafilm ${ }^{\circledR}$ was used, and the formation of filmy avascular adhesion in the control group (Tab. 2). While there was an intensive vascular or avascular adhesion in 8 (53\%) of the control group, it was present in only $3(20 \%)$ of the treatment group ( $p<0.05)$. Adhesion was totally prevalent in 7 (46.6\%) rabbits of the control group, whereas this

Tab. 2. Distribution of adhesion seriousness score.

\begin{tabular}{lcccc}
\hline & G0 & G1 & G2 & G3 \\
\hline Treatment group (number of rabbits) & 10 & 2 & 3 & 0 \\
Control group (number of rabbits) & 3 & 1 & 8 & 3 \\
\hline
\end{tabular}

Tab. 3. Distribution of adhesion prevalence score.

\begin{tabular}{lcccc}
\hline & G0 & G1 & G2 & G3 \\
\hline Treatment group (number of rabbits) & 10 & 2 & 1 & 2 \\
Control group (number of rabbits) & 3 & 3 & 2 & 7 \\
\hline
\end{tabular}

\begin{tabular}{ll}
\hline Adhesion Area Classification & Adhesion Seriousness Classification \\
\hline Grade $0:$ No adhesion & Grade- $0:$ No adhesion \\
Grade $1:$ There is adhesion in $1-25 \%$ of the area & Grade- $1:$ Thin filmy avascular \\
Grade $2:$ There is adhesion in $26-50 \%$ of the area & Grade- $2:$ Intensive vascular and avascular \\
Grade $3:$ There is adhesion in more than $50 \%$ of the area & Grade- 3 : Separated with cohesive sharp dissection \\
\hline
\end{tabular}


figure was 2 (13.3 \%) in the treatment group (p < 0.01) (Fig. 3). Prevalence of adhesion in the treatment group had decreased significantly. There was no significant difference between the two groups in the prevalence 1 and 2 scores (Tab. 3).

\section{Discussion}

Intraabdominal adhesions occur between the areas where the surface of the peritoneum is damaged and usually between the greater omentum and stomach wall (1-6). While very few of those who have undergone a surgery suffer from the symptoms related to postoperative adhesions (POA) (7), all gastrointestinal surgeons encounter patients with POAs in their daily lives (7). Are POAs really a problem? Ellis et al investigated problems arising from POAs in order to find an answer to this question in 1999 (8). In America, more than 400,000 surgical interventions are performed every year to treat POA complications, and this costs about 1.3 million dollars annually (3). Adhesion related complications account for $30 \%$ of the patients who were hospitalized again after a colorectal surgery (6). In a survey conducted by Scott Combes et al among general surgeons it was found that $76 \%$ of the surgeons performed 2 interventions due to POA, while $31 \%$ of them conducted more than 5 interventions (9). Peritoneal adhesions are the underlying cause of $32 \%$ of acute intestinal obstructions and of $65-75 \%$ of small bowel obstructions. This complication accounts for $2.6-3.3 \%$ of all indications for laparotomy (10). POA development risk can be significantly reduced if the surgeon complies with microsurgical principles. These principles include delicate tissue manipulation, total hemostasis, little or nonreactive suture and minimum use of electrocautery (11). More time is spent to enter the peritoneum cavity in patients with POA who have undergone a surgical intervention previously (12).

Implementation of a good surgical technique seems to be the best way of reducing POAs to a minimum. These techniques can be listed as minimum tissue trauma, total hemostasis, avoiding ischemia, preventing excessive drying of intra-abdominal organs, avoiding infection and making sure that there are no remains of foreign objects (13). Ischemia is one of the most prevalent results leading to POA. Laparoscopic cholecystectomies, where mono-polar and ultrasonic energy, a leading cause of ischemia, are used, were compared in terms of postoperative pain, duration of stay in hospital and time spent before a return to work. Fewer inflammatory responses and fewer POA formations were observed in patients on whom ultrasonic energy was used (14). Previous adhesions recurred in about $66 \%$ of the patients, on whom adhesiolysis was performed, using methods such as electrocautery, sharp dissection, $\mathrm{CO}_{2}$, Argon and KTP laser, but new adhesions developed in $12 \%$ of them (15). The questions pertaining to what the factors that affect the formation of adhesions are (direct and indirect clinical results of POAs and surgical technical measures), still remain to be answered (16). It is frequently reported in the relevant literature that POAs lead to serious morbidity. While the rate of POA was 75-95 \% in laparotomy, it was found to be $12-40 \%$ in laparoscopy. The number of new adhesions after laparoscopic adhesiolysis was found to be significantly lower than adhesions that formed after adesiolysis was performed with laparotomy (15). In experiments on animals and volunteering patients, Seprafilm ${ }^{\circledR}$ was used in surgeries that required a second look laparotomy, and POAs decreased significantly (17). In studies that used Seprafilm ${ }^{\circledR}$, reliability of the studies was increased by omitting those that used agents such as corticosteroids, salicylates and heparin, all of which affect the formation of adhesions. The results of the study were evaluated by independent surgeons and recorded on video. It is important that the area where Seprafilm ${ }^{\circledR}$ is applied is sufficiently dry, hemostasis is performed well and there is no space left between Seprafilm ${ }^{\circledR}$ and the tissue (18). One study suggested that treatment and control groups should be observed for at least 10 years in order to better evaluate POA related small intestine obstructions (15). In a period of over 10 years, Seprafilm ${ }^{\circledR}$ use saves 383 dollars for the patient and 1122 dollars for each patient socioeconomically (19). The fact that Seprafilm ${ }^{\circledR}$ is thin and easily wrinkles, causes difficulty in application, especially in abdomens that are hard to recover, and in small incisions (20). The ideal adhesion barrier should meet the following criteria: (1) it should separate tissues effectively; (21) it should have a half-life that is long enough to stay in peritoneum for the critical 7 day period, which is the time for peritoneum to heal; (7) it should be absorbed and metabolized without triggering an obvious inflammatory tissue response; (8) it should stay effective and active when there is blood in the environment; (3) it should not interrupt healing of the scar; (22) and it should not contribute to bacterial increase (3). In conclusion, Seprafilm ${ }^{\circledR}$ use reduces the rate of POA significantly when there are ischemic, damaged and foreign objects. The rules (which have accumulated since the emergence of surgery constitute surgical principles and require painstaking and aesthetic work) are still maintained to be the most important in the prevention of POA.

\section{References}

1. Menzies D, Ellis H. Intestinal Obstruction from adhesions: How Big is the Problem? Ann R Coll Surg Engl 1990; 72: 60-63.

2. Ward BC, Panitch A. Abdominal Adhesions: Current and Novel Therapies. J Surg Res 2009; 165 (1): 91-111.

3. González-Quintero VH, Cruz-Pachano FE. Preventing Adhesions in Obstetric and Gynecologic Surgical Procedures. Rev Obstet Gynecol 2009; 2 (1): 38-45.

4. Burns JW, Colt MJ, Burgees LS, Skinner KC. Preclinical Evaluation of Seprafilm ${ }^{\circledR}$ Biresorbable Membrane. Eur J Surg Suppl 1997; 577: 40-48.

5. Beck DE. The Role of HA Membrane in Adhesion Prevention. Eur J Surg Suppl 1997; 577: 49-55.

6. Nunobe S, Hiki N, Fukunaga T et al. Previous Laparotomy is not a Contraindication to Laparoscopy-Assisted Gastrectomy for Early Gastric Cancer.

7. Ellis H. The Clinical Significance of Adhesions: Focus on Intestinal Obstruction. Eur J Surg Suppl, 1997; 577: 5-9.

8. Diamond MP, Burns EL, Accomando B, Mian S, Holmdahl L. Seprafilm ${ }^{\circledR}$ Adhesion Barrier: (1) a Review of Preclinical, Animal, and Human Investigational Studies. Gynecol Surg, 2012; 9: 237-245. 


\section{9-752}

9. Scot Combes DM, Vipond MN, Thomson JN. General Surgeons Attitudes to the Treatment and Prevention of Abdominal Adhesion. An Rcol Surg Engl 1993; 75: 123-128.

10. Fevang BT, Fevang J, Lie SA et al. Long-Term Prognosis after Operation for Adhesive Small Bowel Obstruction. Ann Surg 2004; 240 (2): 193-201.

11. Johns A. Evidence-based Prevention of Post-operative Adhesions. Human Reproduction, Update 2001; 7(6): 577-579.

12. van der Wal JBC et al. Adhesion Prevention During Laparotomy: Long-Term Follow-Up of a Randomized Clinical Trial. Ann Surg 2011; 253 (6): 1118-1121.

13. Tulandi T, Al-Jaroudi D. Nonclosure of Peritoneum: a Reappraisal. Am J Obstet Gynecol 2003; 189: 609-612.

14. Sasi W. Dissection by Ultrasonic Energy Versus Monopolar Electrosurgical Energy in Laparoscopic Cholecystectomy. JSLS 2010; 14: 23-34.

15. Vetere PF et al. Strategies to Minimize Adhesion Formation after Surgery. JSLS 2011; 15: 350-354.

16. Quaissi M, Gaujoux S, Veyrie N, Deneve E, Brigand C, Castel B et al. Post-operative Adhesions after Digestive Surgery: Their Incidence and Prevention: Review of the Literature. J Visc Surg 2012; 149: e104-e114.
17. Dinsmore RC, Calton WC. Prevention of Adhesion to Poli-prolen Mesh in a Rabbit Model. Amer Surg 1999; GS: 384-387.

18. Alexonder H, De Cherney, BS, Di Zenega GS. Clinical Problem of Intraperitoneal Postsurgical Adhesion Formation Following General Surgery and the Use of Adhesion Prevention Barriers. Surg Clin North Amer 1997; 77 (3).

19. Bristow RE, Santillan A, Diaz-Montes TP et al. Prevention of Adhesion Formation after Radical Hysterectomy Using a Sodium Hyaluronatecarboxymethylcellulose (HA-CMC) Barrier: a Cost Effectiveness Analysis. Gynecol Oncol 2007; 104: 739-746.

20. Oncel M, Remzi FH, Senegore AJ, Connor JT, Fazio VW. Comparison of Novel Liquid (Adcon-P) Sodium Hyaluronate and Carboxymethylcellulose Membrane (Seprafilm ${ }^{\circledR}$ ) Postsurgical Adhesion Formation in a Murine Model. Dis Colon Rectum 2003; 46: 187-191.

21. Nunobe S, Hiki N, Fukunaga T et al. Previous Laparotomy is not a Contraindication to Laparoscopy-Assisted Gastrectomy for Early Gastric Cancer. World J Surg 2008; 32: 1466-1472.

22. Parker MC, Wilson MS, Menzies D et al. The SCAR-3 Study: 5-year Adhesion-Related Read Mission Risk Following Lower Abdominal Surgical Procedures. Colorectal Dis 2005; 7 (6): 551-558. 